\title{
The conundrum of using hyperoxia in COVID-19 treatment strategies: may intermittent therapeutic hyperoxia play a helpful role in the expression of the surface receptors ACE2 and Furin in lung tissue via triggering of HIF-1a?
}

\author{
Andreas Koch ${ }^{1 *}$, Wataru Kähler ${ }^{1}$, Sebastian Klapa', Bente Grams ${ }^{1}$ and Pieter- Jan A. M. van Ooij ${ }^{2}$
}

\footnotetext{
* Correspondence: a.koch@iem.unikiel.de

${ }^{1}$ Joint Section of Maritime Medicine, Naval Institute of Maritime Medicine and Christian-Albrechts-University Kiel, Kiel, Germany

Full list of author information is available at the end of the article
}

\section{Introduction}

In the current pandemic of severe acute respiratory syndrome corona virus 2 (SARS$\mathrm{CoV}-2)$, the therapeutic administration of oxygen is a common procedure in order to mitigate patient's hypoxia in the course of severe corona virus disease 2019 (COVID-19) pneumonia. However, additional oxygen causes a variety of well-known side-effects, impacting a number of systems regulating cardiovascular and respiratory homeostasis as well as reactive oxygen species (ROS)-production via oxidative stress.

In this article, we want to focus on intermittent changes in lung and tissue oxygenation, as changes in local $\mathrm{pO}_{2}$ may be able to trigger one of the key effectors of cellular oxygen-sensing, hypoxia-inducible factor- $1 \alpha$ (HIF-1 $\alpha)$ and, in downstream, the expression of angiotensin-converting enzyme-2 (ACE2) and Furin.

Recently, evidence has been found that the ACE2-receptor in lung tissue, in combination with Furin, is essential for the development of COVID-19 [1-3].

Besides, there is also new information, that in contrast a severe course of lung complication of COVID-19 is correlated with reduced ACE2 on the cell surface due to shedding of the ACE2-receptor from the cell surface [4] and thus, with an insufficient angiotensin-(2) (AT2)-conversion to angiotensin-(1-7) (AT1-7).

This finding, that reduced ACE2 on lung cell surfaces is correlated with lung damage due to an uncontrolled renin-angiotensin system (RAS) cascade, is supported by recent data about effects of long-lasting hyperoxia on pulmonary tissue [5-10].

Thus, in the course of COVID-19, ACE2 plays a complex role: high levels of ACE2receptors on the cell surface in combination with Furin may facilitate SARS-Cov2-

(c) The Author(s). 2020 Open Access This article is licensed under a Creative Commons Attribution 4.0 International License, which permits use, sharing, adaptation, distribution and reproduction in any medium or format, as long as you give appropriate credit to the original author(s) and the source, provide a link to the Creative Commons licence, and indicate if changes were made. The images or other third party material in this article are included in the article's Creative Commons licence, unless indicated otherwise in a credit line to the material. If material is not included in the article's Creative Commons licence and your intended use is not permitted by statutory regulation or exceeds the permitted use, you will need to obtain permission directly from the copyright holder. To view a copy of this licence, visit http://creativecommons.org/licenses/by/4.0/. 
intrusion during the very early phase of infection, but in case of severe COVID-19 with pulmonary complications finally low levels of ACE2 can finally worsen the situation due to insufficient AT2-conversion.

In both situations, in the beginning and in the pulmonary complication phase, manipulation of inspiratory $\mathrm{pO}_{2}$ may be a way to influence the levels of ACE2 and Furin with beneficial effects on the further course of the disease.

\section{Role of angiotensin-converting enzyme-2 in the course of COVID-19}

Like in many other tissues, lung cells also have a local RAS [11], which influences the pathogenesis of lung injury via cellular effects, like changes in vascular permeability, vascular tone, fibroblast activity, or alveolar epithelial cell apoptosis [12, 13]. ACE2 plays a pivotal role in the RAS cascade starting with angiotensinogen and ending with AT1-7 [11]. The latter enzyme has a downregulating effect on this RAS cascade and thus limits inflammation and fibrosis [11, 14]. However, a decrease in ACE2 activity, like in longerlasting hyperoxia, diminishes the conversion of AT2 into AT1-7, thus leading to an increment of AT2 [7]. The increased presence of AT2 initiates, among others, the development of fibrosis in the lung and in addition, might significantly contribute to an uncontrolled inflammation, e.g., severe increases in interleukin 6 (IL-6) [15].

As described above, a similar decrease in ACE2 has also been seen in COVID-19 with severe pulmonary complications, which might initiate comparable negative consequences, that arise from insufficient AT2-inactivation [4].

\section{Role of Furin in the course of COVID-19}

Furin, also known as paired basic amino acid cleaving enzyme (PACE) or proprotein convertase subtilisin/kexin type-3 (PCSK3), is identified as the prototype of the currently known mammalian subtilisin/kexin-like proprotein convertases and is involved in the activation of precursors of growth factors, viral glycoproteins, and adhesion receptors via endoproteolytic cleavage at basic amino acid residues [16, 17]. In detail, bioinformatic studies identified more than 100 Furin cleavage sites in mammalian proteins, e.g., cytokines, hormones, receptors, and albumin [18]. On the other hand, most viral envelope glycoproteins need to be proteolytically cleaved for mediating the viral entry into the host cells, such as herpesvirus, retrovirus, or corona virus [17]. Indeed, in COVID-19, the cleavage function of Furin facilitates the penetration of SARSCoV-2 into the cell after binding to the ACE2-receptor $[2,19]$. The localization of Furin involves intracellular compartments as well as the cell surface and may explain its ability to process an expanded variety of substrates. In animal models, for instance, it is essential in the astrocyte neuroprotection mechanisms during hypoxia in acute cerebral ischemia [20].

\section{COVID-19 and oxygen therapy}

In the current pandemic situation of SARS-CoV2, there are, among all the other numerous therapeutic attempts, also approaches using (hyperbaric) hyperoxia as an additional option in the treatment of patients suffering COVID-19. Currently, there are seven clinical trials in preparation using hyperbaric oxygenation therapy (HBOT) as a therapeutic (adjuvant) option in COVID-19 patients with respiratory distress 
(NCT04343183; $\quad$ NCT0433208; $\quad$ NCT04344431; $\quad$ NCT04358926; $\quad$ NCT04386265; NCT04409886; NCT04327505).

However, nearly nothing is even known about the effect of therapeutic administered oxygen on the expression of ACE2 and Furin in respiratory tissues.

Besides, there is a body of evidence from diving and hyperbaric medicine, intensive care, and neonatology that hyperoxia is able to harm the lung [21].

In diving as well as in hyperbaric oxygen therapy (HBOT), oxygen is delivered to the body with increased partial pressures, ranging from slightly supranormal in SCUBAdiving to up to more than the 15-fold in HBOT [22].

In diving medicine and HBOT, the hyperoxia-dependent risk of lung damage is calculated by the UPTD-formula (units of pulmonary toxicity dose), and similar risk assessments are used in anesthesiology and intensive care medicine [23, 24].

Hyperoxia-induced lung reactions may range from early signs of inflammation up to severe impairment of lung function and are discussed to be one of the major contributors to the development of the acquired respiratory distress syndrome (ARDS) as a complication of long-time ventilation in intensive care [21, 25].

Furthermore, in neonatology, hyperoxia is known to have the capability of inducing severe lung reactions, which, in the end, can result in lung fibrosis $[8,10,26]$.

In addition, experimental data show that longer-lasting administration of oxygen to fetal lung cells results in a downregulation of ACE2 and is related to the development of lung fibrosis [8-10].

In this context of hyperoxia-inducible lung damage and the certain role of ACE2 in its pathophysiology, there is a need to closer focus on the role of HIF- $1 \alpha$, since it plays a key role in cellular oxygen sensing and is one of the main factors regulating the expression of ACE2 and Furin.

\section{Role of HIF-1a in cellular oxygen sensing}

The substantial mechanisms responsible for hyperoxia-induced lung damage are still under investigation with a certain role of oxidative stress and a number of further mechanisms, which include pathways of hypoxia-sensing and reaction. More importantly, there is information that the transcription factor HIF-1 $\alpha$ and its induced factors ACE2 and Furin may thereby play a significant role [7].

HIF-1 $\alpha$, whose expression is known to be dependent from cellular oxygen supply, has been identified to be one factor regulating the mRNA-expression for the synthesis of ACE2 and Furin [27-29].

Hypoxia is the natural trigger for upregulation of HIF-1 $\alpha$ [30, 31]; however, there is evidence that this effect attenuates over time [30]. Vice versa, in longer-lasting hyperoxia, HIF-1 $\alpha$ becomes downregulated [32-34].

Noteworthy, there is some evidence that intermittent hyperoxia, i.e., changes between phases with elevated $\mathrm{pO}_{2}$ and prior conditions (e.g., in HBOT), can also act as a trigger to increase HIF-1 $\alpha$-level [35]. This phenomenon, formerly entitled as "normobaric oxygen paradox," is discussed to be due to relative hypoxia after short phases of elevated oxygen tension [36].

As one central sensing mechanism, increased intramitochondrial ROS-production due to hypoxia as well as intermittent hyperoxia may initiate stabilization of active HIF-1 $\alpha$ [37-39], which induces increased ACE2- and Furin-expression [27-29]. 


\section{Hypothesis}

As HIF- $1 \alpha$ and in consequence HIF- 1 seem to be central factors for the expression of ACE2 and Furin, and as the stabilization of active HIF-1 $\alpha$ is oxygen-dependent, the therapeutic administration of oxygen might have a significant influence on ACE2- and Furin-expression.

Two different consequences can be drawn from the above-mentioned interactions between changes in $\mathrm{pO}_{2}$ and the expression of HIF-1 $\alpha$ :

First, a longer-lasting administration of additional oxygen may induce a reduction in HIF- $1 \alpha$ and in consequence in ACE2 and Furin. A reduced number of binding sites for the SARS-CoV-2 virus may be beneficial in the very early phase of the infection with respect to virus-intrusion.

However, it is questionable, whether the administration of hyperoxia is practicable in the very early infection phase, even in risk patients.

Second, since both manifest hypoxia itself as well as administration of intermittent hyperoxia with consecutive relative hypoxia occurring after completion, seem to be able to induce an increased HIF- $1 \alpha$-expression, this mechanism may be a chance to increase critically reduced levels of ACE2 and Furin in case of severe pulmonary complications. However, in severe pneumonia, the administration of supplemental oxygen is often essential in order to avoid tissue hypoxia in the patient, and thus, a triggering of HIF-1 $\alpha$ expression via a withholding of oxygen seems not to be feasible.

On the other hand, since intermittent phases of hyperoxia with consecutive-only relative hypoxia may also result in a HIF- $1 \alpha$-induction similar to real hypoxia, the administration of phases with intermittent hyperoxia on the ICU seems to be a chance to increase the critically reduced ACE2-receptor levels in severe COVID-19 pneumonia. This might help to re-establish adequate AT2-conversion into AT(1-7) and thus, to preserve a functional RAS-cascade. Whether a parallel triggered increase in Furin may have additional positive effects is unknown and needs to be elucidated.

Typical hyperbaric oxygenation therapy (HBOT; 2.0-2.5ata) sessions with their changes between 100\% oxygen and "air breaks" (short phases of ambient air for pulmonary protection, depending on the used schedule) under pressure during therapy and "only" normobaric conditions after completion may induce a number of relative hypoxic phases. Thus, besides overall enhanced tissue oxygenation, these relative hypoxic phases may induce the discussed increase in HIF-1 $\alpha$-expression over time.

Up to now, this control circuit has scarcely been investigated in relation with the possible clinical consequences in COVID-19-therapy. Yet, there might be a chance that the administration of intermittent short phases of hyperoxia may be helpful to reduce some complications of COVID-19 pneumonia when the development of the clinical picture makes it necessary to take critically reduced ACE2-levels into account.

Further basic research in human cells and tissues is needed to precisely elucidate the underlying mechanisms and its usability as an additional therapy for COVID-19 in both, the very early infection and the severe COVID-19 pneumonia. 
oxygen species; SARS-CoV-2: Severe acute respiratory syndrome corona virus 2; SCUBA: Self-containing underwater breathing apparatus; UPTD: Units of pulmonary toxicity dose

\section{Acknowledgements}

Not applicable.

\section{Authors' contributions}

All authors contributed to the development of hypothesis. AK contributed to the organization and writing of the manuscript. WK contributed to the literature research, writing, and special focus on HIF-1a. SK contributed to the literature research, writing, and special focus on ACE2 and Furin. BG contributed to the literature research and writing. PvO contributed to the literature research, writing, and special focus on lung and oxygen. All authors read and approved the final manuscript.

\section{Funding}

Governmental. Open access funding provided by Projekt DEAL.

\section{Availability of data and materials}

Not applicable.

\section{Ethics approval and consent to participate}

Not applicable.

\section{Consent for publication}

Not applicable.

\section{Competing interests}

No competing interests.

\section{Author details}

${ }^{1}$ Joint Section of Maritime Medicine, Naval Institute of Maritime Medicine and Christian-Albrechts-University Kiel, Kiel, Germany. ${ }^{2}$ Diving Medical Center, Royal Netherlands Navy, Den Helder, and Respiratory Department of the Academic Medical Center, Amsterdam, the Netherlands.

Received: 27 May 2020 Accepted: 10 July 2020

Published online: 15 September 2020

\section{References}

1. Rivellese F, Prediletto E (2020) ACE2 at the Centre of COVID-19 from paucisymptomatic infections to severe pneumonia. Autoimmun Rev 102536 . https://doi.org/10.1016/j.autrev.2020.102536

2. Coutard B, Valle C, de Lamballerie X, Canard B, Seidah NG, Decroly E (2020) The spike glycoprotein of the new coronavirus 2019-nCoV contains a furin-like cleavage site absent in CoV of the same clade. Antivir Res 176:104742 .https://doi.org/10.1016/j.antiviral.2020.104742

3. Veerdonk F, Netea M, van Deuren M, van der Meer J, de Mast Q, Brüggemann R, van der Hoeven H (2020) Kinins and cytokines in COVID-19: a comprehensive pathophysiological approach. www.preprints.org. https://doi.org/10.20944/ preprints202004.0023.v1

4. Tseng Y-H, Yang R-C, Lu T-S (2020) Two hits to the renin-angiotensin system may play a key role in severe COVID-19. Kaohsiung J Med Sci https://doi.org/10.1002/kjm2.12237

5. Sturrock BR, Milne K, Chevassut TJ (2020) The renin-angiotensin system - a therapeutic target in COVID-19? Clin med clinmed.2020-0146. https://doi.org/10.7861/clinmed.2020-0146

6. Imai Y, Kuba K, Rao S, Huan Y, Guo F, Guan B, Yang P, Sarao R, Wada T, Leong-Poi H, Crackower MA, Fukamizu A, Hui CC, Hein L, Uhlig S, Slutsky AS, Jiang C, Penninger JM (2005) Angiotensin-converting enzyme 2 protects from severe acute lung failure. Nature 436:112-116. https://doi.org/10.1038/nature03712

7. Fang Y, Gao F, Liu Z (2019) Angiotensin-converting enzyme 2 attenuates inflammatory response and oxidative stress in hyperoxic lung injury by regulating NF-KB and Nrf2 pathways. QJM Mon J Assoc Physicians 112:914-924 . https://doi. org/10.1093/qjmed/hcz206

8. Oarhe Cl, Dang V, Dang M, Nguyen H, Gopallawa I, Gewolb IH, Uhal BD (2015) Hyperoxia downregulates angiotensinconverting enzyme-2 in human fetal lung fibroblasts. Pediatr Res 77:656-662 . https://doi.org/10.1038/pr.2015.27

9. Mohamed TL, Nguyen HT, Abdul-Hafez A, Dang VX, Dang MT, Gewolb IH, Uhal BD (2016) Prior hypoxia prevents downregulation of ACE-2 by hyperoxia in fetal human lung fibroblasts. Exp Lung Res 42:121-130 . https://doi.org/10. 3109/01902148.2016.1157712

10. Gandhi C, Uhal BD (2016) Roles of the angiotensin system in neonatal lung injury and disease. JSM Atheroscler 1:1014

11. Iwai M, Horiuchi M (2009) Devil and angel in the renin-angiotensin system: ACE-angiotensin II-AT1 receptor axis vs. ACE2-angiotensin-(1-7)-mas receptor axis. Hypertens Res Off J Jpn Soc Hypertens 32:533-536 . https://doi.org/10.1038/ hr.2009.74

12. Marshall RP (2003) The pulmonary renin-angiotensin system. Curr Pharm Des 9:715-722 . https://doi.org/10.2174/ 1381612033455431

13. Filippatos $\mathrm{G}$, Tilak M, Pinillos $\mathrm{H}$, Uhal BD (2001) Regulation of apoptosis by angiotensin II in the heart and lungs (review). Int J Mol Med 7:273-280. https://doi.org/10.3892/ijmm.7.3.273

14. Zhang PX, Han CH, Zhou FJ, Li L, Zhang HM, Liu WW (2016) Renin-angiotensin system and its role in hyperoxic acute lung injury. Undersea Hyperb Med J Undersea Hyperb Med Soc Inc 43:239-246 
15. McGonagle D, Sharif K, O'Regan A, Bridgewood C (2020) The role of cytokines including interleukin-6 in COVID-19 induced pneumonia and macrophage activation syndrome-like disease. Autoimmun Rev 19:102537 . https://doi.org/10. 1016/j.autrev.2020.102537

16. Nakayama K (1997) Furin: a mammalian subtilisin/Kex2p-like endoprotease involved in processing of a wide variety of precursor proteins. Biochem J 327 ( Pt 3):625-635 . https://doi.org/10.1042/bj3270625

17. Braun E, Sauter D (2019) Furin-mediated protein processing in infectious diseases and cancer. Clin Transl Immunol 8 : e1073. https://doi.org/10.1002/cti2.1073

18. Tian S, Huang Q, Fang Y, Wu J (2011) FurinDB: a database of 20-residue furin cleavage site motifs, substrates and their associated drugs. Int J Mol Sci 12:1060-1065. https://doi.org/10.3390/ijms12021060

19. Liu PP, Blet A, Smyth D, Li H (2020) The science underlying COVID-19: implications for the cardiovascular system. Circulation. https://doi.org/10.1161/CIRCULATIONAHA.120.047549

20. Chen Y, Zhang J, Deng M (2015) Furin mediates brain-derived neurotrophic factor upregulation in cultured rat astrocytes exposed to oxygen-glucose deprivation. J Neurosci Res 93:189-194 . https://doi.org/10.1002/jnr.23455

21. van Ooij P-JAM, Sterk PJ, van Hulst RA (2016) Oxygen, the lung and the diver: friends and foes? Eur Respir Rev Off J Eur Respir Soc 25:496-505. https://doi.org/10.1183/16000617.0049-2016

22. Clark JM, Lambertsen CJ (1971) Pulmonary oxygen toxicity: a review. Pharmacol Rev 23:37-133

23. Bardin H, Lambertsen C (1970) A quantitative method for calculating pulmonary toxicity: use of the 'unit pulmonary toxicity dose' (UPTD). Institute for environmental medicine report. University of Pennsylvania, Philadelphia

24. Castagna O, Bergmann C, Blatteau JE (2019) Is a 12-h nitrox dive hazardous for pulmonary function? Eur J Appl Physiol 119:2723-2731 . https://doi.org/10.1007/s00421-019-04248-w

25. Hafner S, Beloncle F, Koch A, Radermacher P, Asfar P (2015) Hyperoxia in intensive care, emergency, and peri-operative medicine: Dr. Jekyll or Mr. Hyde? A 2015 update. Ann intensive care 5:42 .https://doi.org/10.1186/s13613-015-0084-6

26. Chen C-M, Chou H-C (2018) Human mesenchymal stem cells attenuate hyperoxia-induced lung injury through inhibition of the renin-angiotensin system in newborn rats. Am J Transl Res 10:2628-2635

27. McMahon S, Grondin F, McDonald PP, Richard DE, Dubois CM (2005) Hypoxia-enhanced expression of the proprotein convertase furin is mediated by hypoxia-inducible factor-1: impact on the bioactivation of proproteins. J Biol Chem 280: 6561-6569. https://doi.org/10.1074/jbc.M413248200

28. Krick S, Hänze J, Eul B, Savai R, Seay U, Grimminger F, Lohmeyer J, Klepetko W, Seeger W, Rose F (2005) Hypoxia-driven proliferation of human pulmonary artery fibroblasts: cross-talk between HIF-1alpha and an autocrine angiotensin system. FASEB J Off Publ Fed Am Soc Exp Biol 19:857-859 . https://doi.org/10.1096/fj.04-2890fje

29. Zhang R, Wu Y, Zhao M, Liu C, Zhou L, Shen S, Liao S, Yang K, Li Q, Wan H (2009) Role of HIF-1alpha in the regulation ACE and ACE2 expression in hypoxic human pulmonary artery smooth muscle cells. Am J Physiol Lung Cell Mol Physiol 297:L631-L640 . https://doi.org/10.1152/ajplung.90415.2008

30. Prabhakar NR (2001) oxygen sensing during intermittent hypoxia: cellular and molecular mechanisms. J Appl Physiol Bethesda Md 1985 90:1986-1994 . https://doi.org/10.1152/jappl.2001.90.5.1986

31. Majmundar AJ, Wong WJ, Simon MC (2010) Hypoxia-inducible factors and the response to hypoxic stress. Mol Cell 40: 294-309 . https://doi.org/10.1016/..molcel.2010.09.022

32. Lee PJ, Choi AMK (2003) Pathways of cell signaling in hyperoxia. Free Radic Biol Med 35:341-350 . https://doi.org/10. 1016/s0891-5849(03)00279-x

33. Poff AM, Kernagis D, D'Agostino DP (2016) Hyperbaric environment: oxygen and cellular damage versus protection. Compr Physiol 7:213-234 . https://doi.org/10.1002/cphy.c150032

34. Rocco M, D'Itri L, De Bels D, Corazza F, Balestra C (2014) The "normobaric oxygen paradox": a new tool for the anesthetist? Minerva Anestesiol 80:366-372

35. Cimino F, Balestra C, Germonpré P, De Bels D, Tillmans F, Saija A, Speciale A, Virgili F (2012) pulsed high oxygen induces a hypoxic-like response in human umbilical endothelial cells and in humans. J Appl Physiol Bethesda Md 1985113 : 1684-1689 . https://doi.org/10.1152/japplphysiol.00922.2012

36. Balestra C, Germonpré P (2012) Hypoxia, a multifaceted phenomenon: the example of the "normobaric oxygen paradox " Eur J Appl Physiol 112:4173-4175. https://doi.org/10.1007/s00421-012-2392-y

37. Acker T, Fandrey J, Acker H (2006) The good, the bad and the ugly in oxygen-sensing: ROS, cytochromes and prolylhydroxylases. Cardiovasc Res 71:195-207 . https://doi.org/10.1016/j.cardiores.2006.04.008

38. Qutub AA, Popel AS (2008) Reactive oxygen species regulate hypoxia-inducible factor 1alpha differentially in cancer and ischemia. Mol Cell Biol 28:5106-5119. https://doi.org/10.1128/MCB.00060-08

39. Chen R, Lai UH, Zhu L, Singh A, Ahmed M, Forsyth NR (2018) Reactive oxygen species formation in the brain at different oxygen levels: the role of hypoxia inducible factors. Front Cell Dev Biol 6:132 . https://doi.org/10.3389/fcell.2018.00132

\section{Publisher's Note}

Springer Nature remains neutral with regard to jurisdictional claims in published maps and institutional affiliations. 